\title{
Expression and Function of the C-Class Chemokine Lymphotactin (XCL1) in Wegener's Granulomatosis
}

\author{
SABINE BLASCHKE, PHILIP BRANDT, JOHANNES T. WESSELS, and GERHARD A. MÜLLER
}

\begin{abstract}
Objective. In Wegener's granulomatosis (WG), vasculitic lesions are characterized by prominent infiltration of polymorphonuclear neutrophils (PMN) and T cells, but underlying pathogenic mechanisms remain to be defined. We analyzed the expression and functional role of the C-class chemokine lymphotactin, XCL1, in WG.

Methods. Sera and peripheral blood mononuclear cells (PBMC) were obtained from 16 patients with WG and healthy controls. Serum XCL1 concentrations were measured by ELISA. PBMC were subjected to flow cytometry for activation markers and immunophenotype of XCL1+ T cells. Renal biopsies were analyzed by double-label immunohistochemistry. In vitro stimulation of PMN with XCL1 was performed to study its function.

Results. Flow cytometry demonstrated coexpression of the activation markers CD25, CD69, and HLA-DR in a significantly higher proportion of T cells in WG patients in comparison to controls. XCL1 was found to be mainly expressed in CD4+CD28- T cells in WG patients. In renal biopsies, the presence of XCL1 was only detected within interstitial CD4+ and CD8+ T cells. Functional studies demonstrated a significant enhancement of IL-8 production in isolated PMN after in vitro stimulation with XCL1. There were no significant differences in XCL1 serum concentrations between WG patients and controls $(\mathrm{p}=0.88)$.

Conclusion. Our data indicated increased expression of XCL1 in CD4+ and CD8+ T cells in WG. Considering its function as a lymphocyte-specific chemoattractant, XCL1 might be a key modulator of $\mathrm{T}$ cell recruitment in WG. Functional studies further suggest that XCL1 may support vascular inflammation by induction of release of interleukin 8 in PMN. (First Release Oct 1 2009; J Rheumatol 2009;36:2491-500; doi:10.3899/jrheum.090244)
\end{abstract}

Key Indexing Terms:

WEGENER'S GRANULOMATOSIS CHEMOKINES T LYMPHOCYTES NEUTROPHILS

Wegener's granulomatosis (WG) is a systemic autoimmune disease of unknown etiology characterized by necrotizing granulomatous vasculitis with typical involvement of respiratory tract and kidneys ${ }^{1}$. Rapid progressive glomerulonephritis as one of the most severe complications may cause endstage renal disease in up to $20 \%$ of WG cases. Histopathologically, WG belongs to the systemic vasculitides of small- to medium-size vessels ${ }^{2}$, and may lead to multiple organ failure with concomitant fatal course if initiation of specific immunosuppressive treatment is delayed. Introduction of effective treatment regimens, especially including combinations of corticosteroids and cyclophosphamide, has substantially improved outcome ${ }^{3}$. However, relapses and treatment-related morbidity due to drug-

From the Department of Nephrology and Rheumatology, University of Göttingen, Göttingen, Germany.

Supported by a grant from the research foundation program of the University of Medicine of Göttingen.

S. Blaschke, MD; P. Brandt, Cand. Med.; J.T. Wessels, PhD; G.A. Müller, MD, Professor of Medicine; Department of Nephrology and

Rheumatology, University Medicine of Göttingen, Germany

Address correspondence to Dr. S. Blaschke, Department of Nephrology

and Rheumatology, Georg-August-University, Robert-Koch Str. 40, 37075

Göttingen, Germany. E-mail sblasch@gwdg.de

Accepted for publication June 26, 2009. induced immunosuppression still occur and stress the need for the development of alternative therapeutic strategies by analysis of pathogenic pathways in WG.

In the immunopathogenesis of WG, highly specific antineutrophil cytoplasmic antibodies (cANCA) are directed against a serine proteinase (proteinase 3, PR-3) expressed in granules of neutrophils (and monocytes) and on the surface of tumor necrosis factor- $\alpha$ (TNF- $\alpha$ )-stimulated neutrophils ${ }^{4}$. These antibodies have been shown to play a primary pathogenic role by activating neutrophils and monocytes to release tissue-destructive and proinflammatory mediators, e.g., oxygen radicals ${ }^{5}$ and interleukin 8 (IL-8) ${ }^{6}$. Further, granulomatous inflammation in WG has previously been shown to be characterized by enrichment of T-helper cell type 1 (Th1) CD4+ T cells ${ }^{7}$. Recruitment of neutrophils, CD4+ T cells, and, later on, cytotoxic CD8+ T cells during formation of granulomatous lesions was found to be triggered by activation of tissue-resident $\mathrm{T}$ cells, natural killer (NK) cells, mast cells, and histiocytes. However, the pathogenic mechanisms that promote increased infiltration of activated leukocytes into granulomatous lesions in the pathogensis of WG remain to be elucidated.

Chemokines are secreted, low molecular-weight proteins known to play a crucial role for transendothelial leukocyte

Personal non-commercial use only. The Journal of Rheumatology Copyright (c) 2009. All rights reserved. 
migration and activation along chemoattractant gradients during inflammation ${ }^{8}$. These molecules are structurally related and have been classified according to the organization of the N-terminal conserved cysteine (C) motif into 4 groups, designated $\mathrm{CC}-$, CXC-, CX3C-, and C-class chemokines. CXC- and CC-chemokine classes both include several members, whereas the $\mathrm{C}$ - and $\mathrm{CX} 3 \mathrm{C}$-chemokine subfamilies are each represented so far by only one member, lymphotactin (XCL1) and fractalkine (CX3CL1), respectively. According to their biological activity, CXC-chemokines are found to mainly target neutrophils and $\mathrm{T}$ cells, CC-chemokines generally attract monocytes and $\mathrm{T}$ cells, and both $\mathrm{C}$ - and $\mathrm{CX} 3 \mathrm{C}$-chemokines have a more restricted specificity for $\mathrm{T}$ cells.

Lymphotactin (XCL1), independently observed by Kelner, et al [lymphotactin (Lptn)] ${ }^{9}$, Yoshida, et al [single C motif-1 (SCM-1)] ${ }^{10}$, and Müller, et al [activation-induced, T cell derived, and chemokine-related molecule (ATAC) $]^{11}$, represents the sole member of the C-chemokine subfamily. XCL1 was found to be selectively expressed in activated $\mathrm{CD} 8+\mathrm{T}$ cells and in a small proportion of activated CD4+ $\mathrm{T}$ cells $^{11}$, B-type thymocytes ${ }^{9}$, intraepithelial $\partial$ - type $\mathrm{T}$ cells ${ }^{12}$, mast cells ${ }^{13}$, and NK cells ${ }^{14}$. XCL1 acts via a unique G-protein-coupled receptor $(X C R 1)^{15}$. Surface expression of XCR1 was detected on CD4+ and CD8+ T cells and NK cells as well as on polymorphonuclear neutrophils (PMN) ${ }^{16}$ and B cells. Biological functions of XCL1 were found mainly to include the chemotactic activity for CD4+, CD8+ T cells ${ }^{17,18}$ and NK cells ${ }^{19}$. Expression of XCL1 has been detected in several clinical and experimental models of inflammatory disease including chronic inflammatory bowel disease $^{20}$, autoimmune diabetes ${ }^{21}$, encephalomyelitis ${ }^{22}$, and rheumatoid arthritis (RA) ${ }^{23}$. In renal diseases, expression of XCL1 has been studied in acute allograft rejection ${ }^{24}$ and experimental crescentic glomerulonephritis ${ }^{25}$. Results of these studies support the concept of a potential role of XCL1 in Th1-type inflammatory processes.

Considering the function of XCL1 for T cell recruitment in Th1-driven inflammatory diseases, we analyzed the expression of XCL1 in peripheral blood mononuclear cells (PBMC) and renal biopsies from patients with WG. To characterize its functional role we studied the in vitro effects of XCL1 stimulation in WG-isolated PMN known to express the XCR1 receptor.

\section{MATERIALS AND METHODS}

Patients and samples. PBMC and sera $(10 \mathrm{ml})$ were obtained from $16 \mathrm{WG}$ patients and 16 age and sex-matched healthy volunteer blood donors as controls. All WG patients met the criteria established by the American College of Rheumatology ${ }^{26}$. The mean disease duration was 5.6 years (range 1-12 yrs). Most of the patients received standard disease-modifying antirheumatic drug therapy (azathioprine, methotrexate, cyclophosphamide) and low-dose prednisone ( $<10 \mathrm{mg} /$ day). Patients had a mean disease activity score of 22.1 (range 12-34) at presentation as assessed by the Birmingham Vasculitis Activity Score (BVAS) ${ }^{27}$. Patients' baseline characteristics are summarized in Table 1. At inclusion the BVAS revealed
Table 1. Baseline characteristics of patients with WG.

Characteristic

\begin{tabular}{lc}
\hline No. of patients & 16 \\
Sex M:F & $12: 4$ \\
BVAS, mean (range) & $22.1(12-34)$ \\
cANCA-positive \% & 100 \\
PR-3, mean (range) U/ml & $13.1(0-98)$ \\
CRP, mean (range) $\mathrm{mg} / \mathrm{l}$ & $6.23(3.0-16.5)$ \\
Disease duration, median (range) yrs & $5.6(1-12)$ \\
Therapy & \\
Corticosteroids & 16 \\
Azathioprine & 7 \\
Methotrexate & 6 \\
Cyclophosphamide & 3 \\
\hline
\end{tabular}

BVAS: Birmingham Vasculitis Activity Score ${ }^{27}$; cANCA: antineutrophil cytoplasmic antibody (central); PR-3: proteinase-3 antigen; CRP: C-reactive protein.

clinical activity in 6 patients and clinical remission (inactive WG) in 10 cases.

For immunohistochemistry, renal biopsies from 5 patients with WG were analyzed. Kidney biopsies obtained from 4 patients with benign nephrosclerosis, 2 with IgA nephritis, and 2 with lupus nephritis (WHO class IV) served as controls. Renal biopsy specimens were fixed in formalin and embedded in paraffin until immunohistochemical staining. Patients' characteristics and renal histopathology are summarized in Table 2 .

The study was approved by the local Institutional Review Board and patients' written consent was obtained according to the Declaration of Helsinki.

Flow cytometry of PBMC. PBMC were isolated from heparinized blood samples by Ficoll-Hypaque density centrifugation (Biochrom, Berlin, Germany). For analysis of cell-surface antigens CD4, CD8, CD25, CD69, and HLA-DR, PBMC were resuspended at a density of $2 \times 10^{6}$ cells $/ \mathrm{ml}$ in phosphate buffered saline (PBS) $/ 0.1 \%$ bovine serum albumin (BSA) and stained for cell-surface antigens with fluorochrome-labeled antibodies. Anti-CD4, anti-CD8, anti-CD3, anti-CD25, anti-CD69, and anti-HLA-DR antibodies and isotype control $\left(\mathrm{IgG}_{1} / \mathrm{IgG}_{2 \mathrm{a}}\right)$ were purchased from Becton Dickinson (Heidelberg, Germany). Cells were subsequently fixed in $4 \%$ paraformaldehyde for $15 \mathrm{~min}$ at $4^{\circ} \mathrm{C}$, washed twice in PBS $/ 0.1 \% \mathrm{BSA}$, and finally resuspended in $250 \mu \mathrm{l}$ PBS and subjected to flow cytometric analysis.

To detect XCL1 expression in PBMC, stimulation with phorbol 12-myristate 13-acetate (PMA; 20 ng/ml; Sigma, Deisenhofen, Germany) and ionomycin $(1 \mu \mathrm{g} / \mathrm{ml}$; Sigma) was performed for $5 \mathrm{~h}$ at a density of $2 \times$ $10^{6}$ cells $/ \mathrm{ml}$ in Iscove's modified Dulbecco's medium (Gibco BRL, Eggenstein, Germany) supplemented with $100 \mathrm{IU} / \mathrm{ml}$ penicillin, $100 \mu \mathrm{g} / \mathrm{ml}$ streptomycin, and $10 \%$ fetal calf serum. After $2 \mathrm{~h}$ incubation, brefeldin $\mathrm{A}$ ( $5 \mu \mathrm{g} / \mathrm{ml}$; Sigma) was added to inhibit chemokine release. Unstimulated PBMC were cultured only in the presence of brefeldin A $(5 \mu \mathrm{g} / \mathrm{ml})$. Staining for intracellular XCL1 expression and for cell-surface markers CD3, CD4, CD8, and CD28 was performed as described ${ }^{23}$. PBMC were finally resuspended in $250 \mu \mathrm{lBS} / 0.1 \%$ BSA and subjected to flow cytometry analysis on a 2-laser FACSCalibur cytometer (Becton Dickinson). Dead cells and monocytes were excluded by forward and side-scatter gating. Typically, 10,000 events were acquired and analyzed using Cellquest software. Bivariate dot plots were generated upon data reanalysis to display the frequencies of individual cells coexpressing certain levels of cellsurface antigens and intracellular XCL1. To reveal specificity of staining, target cells were incubated with an isotype-matched immunoglobulin of irrelevant specificity at the same concentration for each fluorescence channel. 
Table 2. Renal biopsies from patients with WG.

\begin{tabular}{|c|c|c|c|c|c|c|c|c|c|c|c|}
\hline \multirow[t]{2}{*}{ Patient } & \multirow[t]{2}{*}{ Age, yrs } & \multirow{2}{*}{$\begin{array}{c}\text { Disease } \\
\text { Onset }\end{array}$} & \multicolumn{3}{|c|}{ Clinical Manifestation } & \multirow[t]{2}{*}{ BVAS } & \multicolumn{3}{|c|}{ Laboratory Result } & \multirow[t]{2}{*}{ Histopathology } & \multirow[t]{2}{*}{ Therapy } \\
\hline & & & ENT & Pulmo & Kidney & & cANCA & $\begin{array}{l}\mathrm{PR}-3 \\
\mathrm{U} / \mathrm{ml}\end{array}$ & $\begin{array}{l}\mathrm{CRP}, \\
\mathrm{mg} / \mathrm{ml}\end{array}$ & & \\
\hline 2 & 45 & 2002 & + & - & + & 21 & $1: 160$ & 33 & 18 & $\begin{array}{l}\text { Focal segmental necrotizing extracapillar } \\
\text { proliferating glomerulonephritis with } \\
\text { mild interstitial nephritis }\end{array}$ & ry CYC, GC \\
\hline 3 & 54 & 2002 & + & - & + & 34 & $1: 160$ & 11 & 42 & $\begin{array}{c}\text { Focal segmental necrotizing } \\
\text { glomerulonephritis }\end{array}$ & $\mathrm{CYC}, \mathrm{GC}$ \\
\hline 4 & 49 & 2002 & - & + & + & 20 & $1: 160$ & 7 & 59 & $\begin{array}{c}\text { Focal segmental necrotizing } \\
\text { glomerulonephritis with mild } \\
\text { interstitial nephritis }\end{array}$ & $\mathrm{CYC}, \mathrm{GC}$ \\
\hline 5 & 29 & 2002 & + & - & + & 8 & $1: 320$ & 34 & 88 & $\begin{array}{l}\text { Diffuse necrotizing glomerulonephritis } \\
\text { with extracapillary proliferation }\end{array}$ & CYC, GC \\
\hline
\end{tabular}

ENT: ear, nose, throat; BVAS: Birmingham Vasculitis Activity Score; cANCA: antineutrophil cytoplasmic antibody; PR-3: proteinase-3 antigen; CRP: C-reactive protein; CYC: cyclophosphamide; GC: glucocorticoids.

ELISA for XCL1. XCL1 levels in sera obtained from patients with WG and controls were measured by a sandwich ELISA as described ${ }^{23}$. Plates were read at $490 \mathrm{~nm}$ with a Tecan ${ }^{\circledR}$ ELISA reader (Tecan, Männedorf, Switzerland). Using the MikroWin ${ }^{\circledR}$ software the standard curve of known XCL1 concentrations was established and used to determine XCL1 levels within the serum samples. The detection limit of the assay was $0.4 \mathrm{ng} / \mathrm{ml}$.

Double-label immunohistochemistry. Double-label immunohistochemistry for XCL1 and cell-surface markers CD4, CD8, and CD68 was performed on paraffin sections of renal biopsy specimens obtained from WG patients and patients with benign nephrosclerosis as controls. Sections $(4-6 \mu \mathrm{m})$ were deparaffinized in xylol $(2 \times 10 \mathrm{~min})$ and rehydrated in a degraded ethanol series $(100 \%, 90 \%, 70 \%$ EtOH). After washing in Tris-buffered saline (TBS) buffer ( $0.5 \mathrm{M}$ Tris, $1.5 \mathrm{M} \mathrm{NaCl}, \mathrm{pH} 7.6$ ) containing $0.5 \%$ Tween 20, sections were treated by microwave for $3 \times 3 \mathrm{~min}$ at $300 \mathrm{~W}$ in citrate buffer $(\mathrm{pH}$ 6.0). After cooling to room temperature, nonspecific binding of antibodies was blocked with heat-inactivated normal goat serum (1:10 in TBS) for $1 \mathrm{~h}$ at room temperature. Sections were then incubated with a polyclonal rabbit anti-human XCL1 antibody (TEBU-Bio, Offenbach, Germany; 1:100 in TBS/1\% BSA) in a humidified chamber overnight at $4^{\circ} \mathrm{C}$. After washing in TBS $/ 0.5 \%$ Tween 20 specifically bound antibody was detected by application of a Cy5-conjugated goat anti-rabbit antibody (Dianova, Hamburg, Germany; $1: 50$ in TBS/1\% BSA) for $30 \mathrm{~min}$ at room temperature. Labeling of cell-surface markers CD4, CD8, and CD 68 was performed by application of a monoclonal mouse anti-human antibody (anti-CD4 mAb, clone NCL-CD4-368; anti-CD8 mAb, clone NCL-CD8-295; anti-CD68 mAb, NCL-CD68-KP1; Novocastra, Dossenheim, Germany) diluted $1: 100$ in TBS/1\% BSA overnight at $4{ }^{\circ} \mathrm{C}$. Sections were thoroughly washed again in TBS/ $0.5 \%$ Tween 20 and specifically bound antibody was subsequently detected by application of a Cy3-conjugated goat anti-mouse antibody (Dianova; 1:100) for $30 \mathrm{~min}$ at room temperature. Negative controls included irrelevant antibodies of the same species as well as omission of the first or second step antibody. Sections were finally mounted in Vectashield ${ }^{\circledR}$ mounting medium (Vector Laboratories, Burlingame, CA, USA) to preserve fluorescence and counterstain DNA with 4',6'-diaminidino-2-phenylindolyl-dihydrochloride (DAPI) to visualize nuclear DNA.

Microscopic analysis. Sections were analyzed using an inverted fluorescence microscope (IX71, Olympus, Hamburg, Germany). The system was equipped with both $\mathrm{HBO}$ and $\mathrm{XBO}$ sources for optimal excitation in combination with high-transmission narrow-band filters (AHF, Tübingen, Germany) for the respective channels. A high-sensitive F-view II extended
16 bit camera connected to a PC with Cell- $\mathrm{F}^{\circledR}$ software (Olympus) was used to record single black and white pictures from every fluorescence channel. These pictures were then merged automatically using the "multifluorescence imaging process" function (MFIP) of the Cell-F software, finally leading to $3 \times 16$ bit color pictures.

Stimulation of PMN with recombinant XCL1. Isolation of PMN from peripheral blood of patients with WG was performed by dextran sedimentation, density gradient centrifugation, and hypotonic lysis of the remaining red blood cells as described ${ }^{28}$. Cell purity was checked by differential cell counting with Wright staining and revealed purity $>98 \%$ in each of the following experiments. PMN were finally washed and resuspended in RPMI-1640 supplemented with $1 \%$ insulin-transferrin-selenium (ITS; Gibco BRL) and $100 \mathrm{IU} / \mathrm{ml}$ penicillin $/ 100 \mu \mathrm{g} / \mathrm{ml}$ streptomycin at a density of $5 \times 10^{6} / \mathrm{ml}$. Cells were subsequently stimulated with human recombinant XCL1 (R\&D Systems, Wiesbaden, Germany) at a concentration of 100 $\mathrm{ng} / \mathrm{ml}$ for $24 \mathrm{~h}$. To control the specificity of XCL1 action, anti-human XCL1 antibody (R\&D Systems) was added to the control wells.

Cell culture supernatants of PMN before and after XCL1 stimulation were collected, and PMN were resuspended in TriZol Reagent (Gibco BRL) for RNA isolation, and quantitative RT-polymerase chain reaction (RT-PCR) performed as described ${ }^{23}$. IL-8 concentrations were measured in cell-free culture supernatants before and after XCL1 stimulation by ELISA (PeliKine, Amsterdam, The Netherlands) according to the manufacturer's instructions. The sensitivity of the assay was $3 \mathrm{pg} / \mathrm{ml}$ for IL- 8 . For kinetic studies PMN were stimulated with $100 \mathrm{ng} / \mathrm{ml} \mathrm{XCL1} \mathrm{and} \mathrm{IL-8} \mathrm{production}$ was measured at timepoints $0,1,2,12$, and $24 \mathrm{~h}$ during incubation. For analysis of dose dependency PMN were stimulated with various concentrations of XCL1 including $100 \mathrm{ng} / \mathrm{ml}, 200 \mathrm{ng} / \mathrm{ml}$, and $500 \mathrm{ng} / \mathrm{ml}$.

Statistical analysis. All values are expressed as mean \pm standard error. Statistical differences between groups were evaluated by Student $t$ test. Statistical analysis of XCL1 serum levels was by Mann-Whitney U test. P values were determined by a 2 -sided calculation. Results were considered to be statistically significant if $\mathrm{p}$ values were $<0.05$. Statistical analysis was performed using Prism 5.0 software (GraphPad, San Diego, CA, USA).

\section{RESULTS}

We analyzed expression of the C-class chemokine lymphotactin (XCL1) in PBMC and renal biopsies as well as XCL1 serum levels in patients with WG. 
Immunophenotype of $\mathrm{CD} 4+$ and $C D 8+T$ cells. To characterize the immunophenotype of $\mathrm{CD} 4+$ and $\mathrm{CD} 8+\mathrm{T}$ cells flow cytometric analysis was performed in PBMC isolated from patients with WG and healthy controls. Results revealed that a significantly higher proportion of both CD4+ (Figure 1a) and CD8+ T cells (Figure 1b) coexpressed the activation markers CD25, CD69, or HLA-DR in WG patients in comparison to healthy controls.

$X C L 1$ expression in PBMC. XCL1 expression in PBMC was analyzed by flow cytometry after intracellular chemokine staining. No constitutive production of XCL1 was detected in unstimulated PBMC from patients with WG or controls. After PMA and ionomycin stimulation, $14.38 \% \pm 2.41 \%$ of CD8+ T cells and $5.2 \% \pm 1.29 \%$ of CD4+ T cells stained
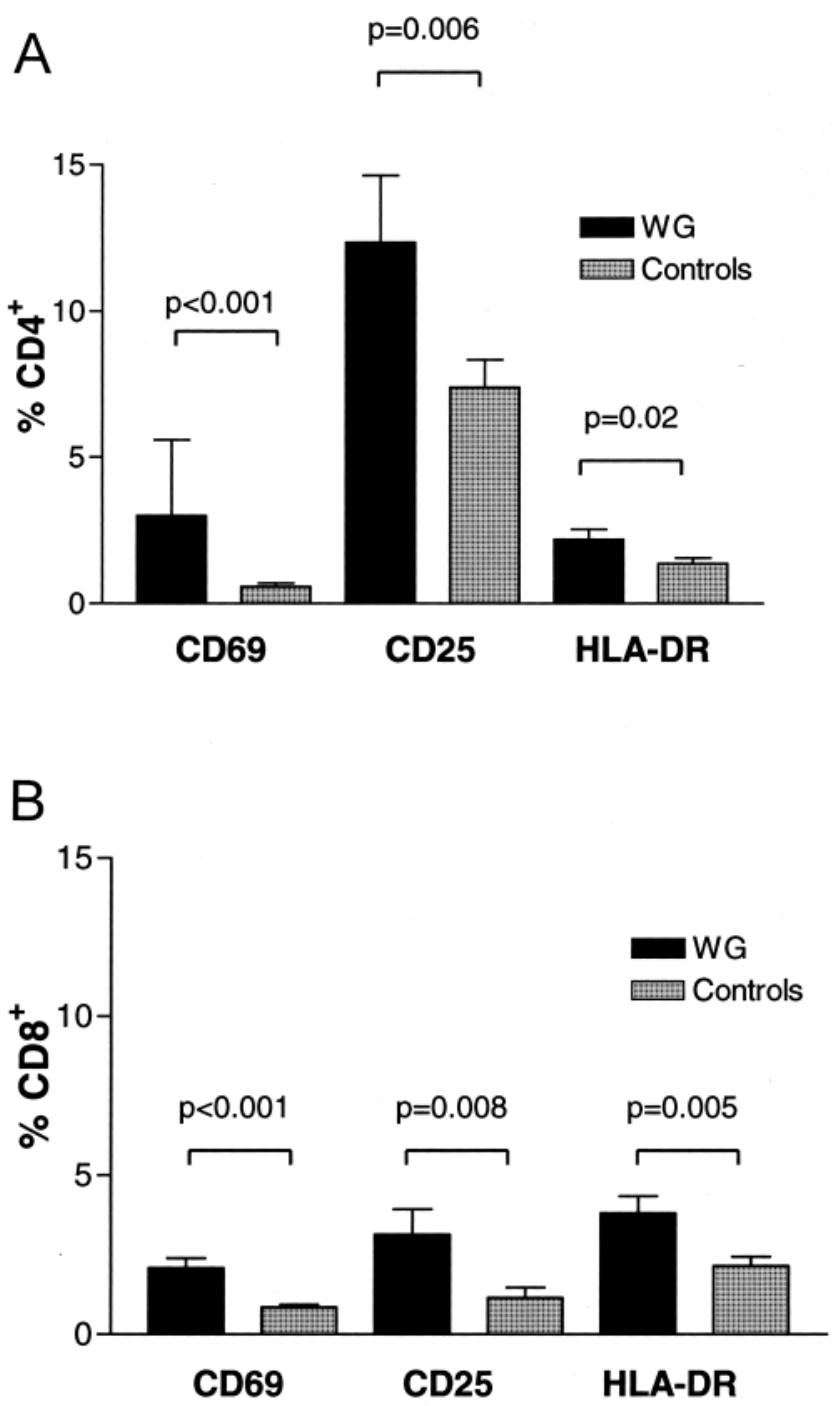

Figure 1. Immunophenotype results of CD4+ (A) and CD8+ (B) T cells in patients with WG and healthy controls. PBMC were isolated from $16 \mathrm{WG}$ patients and 16 controls. A significantly higher proportion of both CD4+ and CD8+ $\mathrm{T}$ cells coexpressed activation markers CD25, CD69, or HLA-DR in WG patients in comparison to controls. positive for XCL1 in WG patients (Figure 2A). XCL1 expression was detected in a significantly greater proportion in both $\mathrm{CD} 4+$ and $\mathrm{CD} 8+\mathrm{T}$ cells of WG patients in comparison to controls ( $\mathrm{p}=0.003, \mathrm{p}=0.001$, respectively). To further characterize the subtype of XCL1-expressing CD4+ and CD8+ T cells, PBMC were stained for the costimulatory CD28 molecule. As shown in Figure 2B, XCL1 was expressed in WG patients in a significantly greater proportion of $\mathrm{CD} 4+\mathrm{T}$ cells deficient for the CD28 surface molecule $(\mathrm{CD} 4+\mathrm{CD} 28-)$ in comparison to controls $(\mathrm{p}=0.007)$. Further, XCL1 was detected mainly in CD8+CD28- T cells in WG patients compared to controls, but these results did not reach statistical significance (Figure 2C). Flow cytometric analyses of $\mathrm{T}$ cells isolated from WG patients with active and inactive disease revealed a significant difference between these patient groups for frequencies of XCL1-positive CD4+ and CD8+ T cells ( $<<0.001$; Figure 2D).

$X C L 1$ expression in renal biopsies from patients with $W G$. To characterize XCL1 expression at sites of active granulomatous inflammation in WG, renal biopsy specimens were analyzed by double-label immunohistochemistry for XCL1 and the cell-surface markers CD4, CD8, and CD68. Renal biopsy specimens were obtained from 5 WG patients prior to initiation of immunosuppressive drug therapy. As shown in Table 2, all patients were characterized by high clinical disease activity as demonstrated by BVAS scores and CRP levels. In addition, all WG patients were cANCA-positive (titer 1:160 to $1: 640$ ) and had PR-3 antibodies (7-279 $\mathrm{U} / \mathrm{ml}$ ). Kidney involvement was characterized by microhematuria with acanthocytes and proteinuria in all cases. Further, histopathological evaluation revealed focal segmental (3/5) or diffuse (2/5) necrotizing glomerulonephritis with extracapillary proliferation (3/5).

Immunohistochemical staining for XCL1 revealed a marked immunofluorescence within granulomatous lesions (Figure 3). XCL1 was predominantly expressed within lymphocytic infiltrates in the interstitium, but was not detected in glomeruli. Using double-labeling for cell-surface antigens CD4, CD8, or CD68, we were able to localize XCL1 in CD4+ (Figure 3A) and in CD8+ (Figure 3B) T cells, but not in resident cells of the monocyte/macrophage lineage (CD68+) (Figure 3C). Colocalization of XCL1 and cell-surface antigens CD4 and CD8 was demonstrated by yellow staining. To discriminate single-antibody staining, intensities of the single-antibody staining were evaluated using Cell- $\mathrm{F}^{\circledR}$ software at the level of the horizontal line and displayed as the inserted intensity curves for $\mathrm{Cy} 3$ and $\mathrm{Cy} 5$. In accord with the flow cytometric analysis of PBMC, CD4+ and CD8+ T cells appeared as the major source of XCL1 in renal biopsies of patients with WG. No staining was observed in cases of isotype controls or in renal biopsies of patients with benign nephrosclerosis, IgA nephritis (data not shown), or lupus nephritis (WHO class IV) (Figure 3D).

Upregulation of IL-8 production in XCL1-stimulated PMN.

Personal non-commercial use only. The Journal of Rheumatology Copyright @ (2009. All rights reserved. 

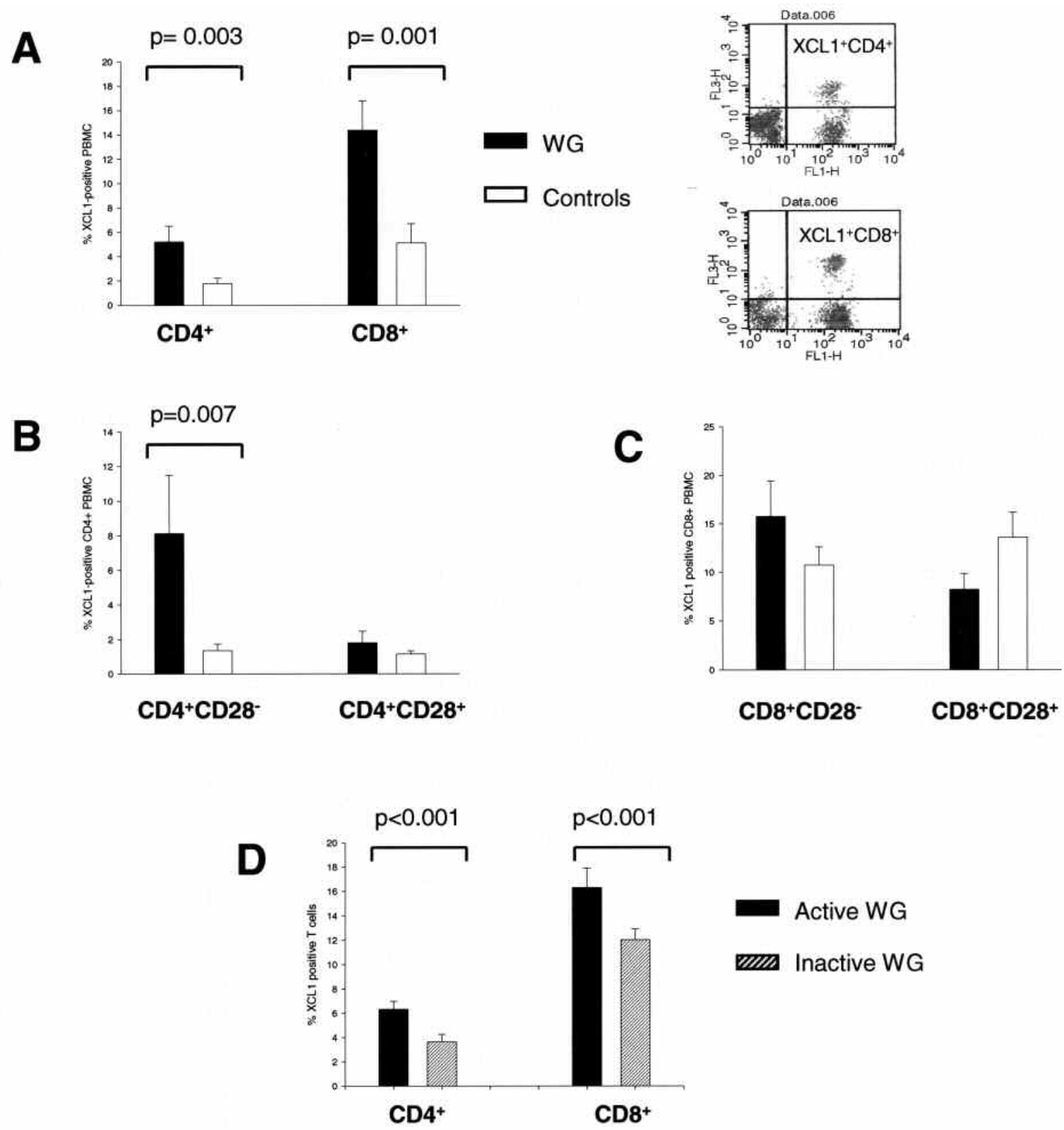

Figure 2. Flow cytometric analysis results of XCL1 expression. PBMC isolated from WG patients and healthy controls were subjected to flow cytometric analysis after stimulation with PMA/ionomycin. XCL1 was expressed in a significantly greater proportion of CD4+ and CD8+ T cells in WG patients in comparison to controls (A). XCL1 was detected in WG patients in a significantly greater proportion of CD4+ T cells lacking the costimulatory molecule CD28 ( $\mathrm{p}=0.007)(\mathrm{B})$. In CD8+ T cells, XCL1 expression was found mainly within the CD8+CD28- T cell subpopulation in WG patients, but there was no statistically significant difference of frequencies of XCL1-expressing CD8+CD28- T cells between WG patients and controls (C). Comparing T cells from patients with active and inactive WG, a significant difference was detected between these patient groups in frequencies of XCL1-positive CD4+ T cells and CD8+ T cells (p < 0.001) (D).

To analyze the functional role of XCL1 in WG, PMN were isolated from WG patients and stimulated in vitro with various concentrations of human recombinant XCL1. cDNA microarray analysis of RNA samples from stimulated and unstimulated cultures suggested that XCL1 may upregulate IL-8 production in cultured PMN. To verify this, supernatants of PMN cultures were analyzed for secreted IL- 8 by
ELISA. As shown in Figure 4, production of IL-8 was significantly upregulated in PMN cultures upon XCL1 stimulation. Stimulation of PMN with $100 \mathrm{ng} / \mathrm{ml} \mathrm{XCL1} \mathrm{increased}$ IL-8 levels up to 20-fold after $24 \mathrm{~h}$ incubation (Figure 4A). This effect could be blocked by addition of the anti-human XCL1 antibody. Upregulation of IL-8 production by XCL1 was shown to be time-dependent (Figure 4B) and 


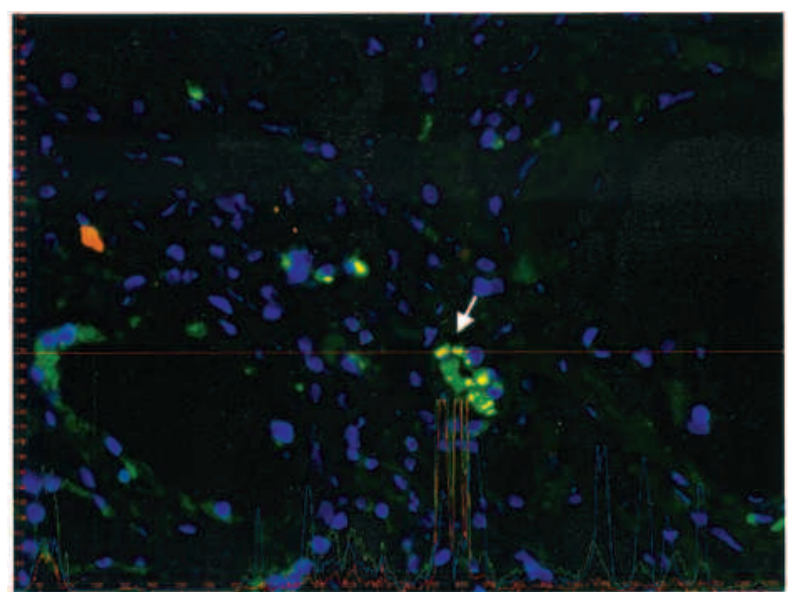

A

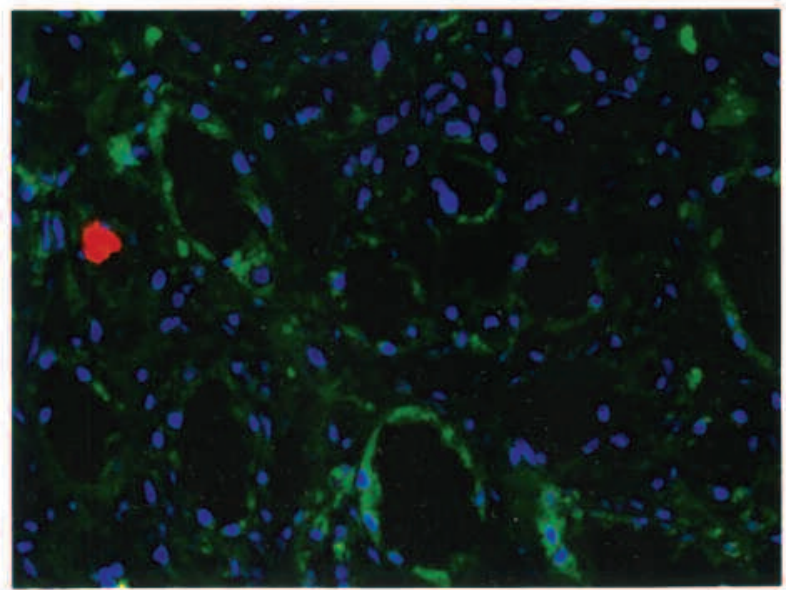

C

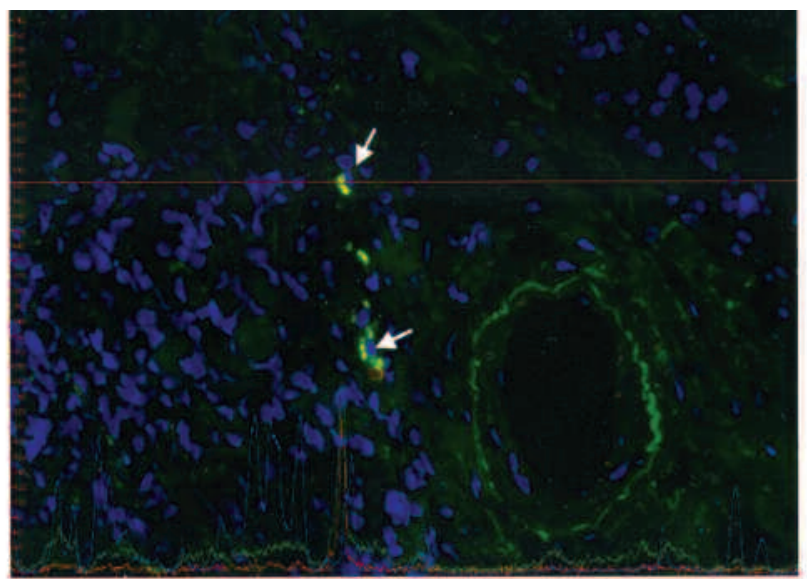

B

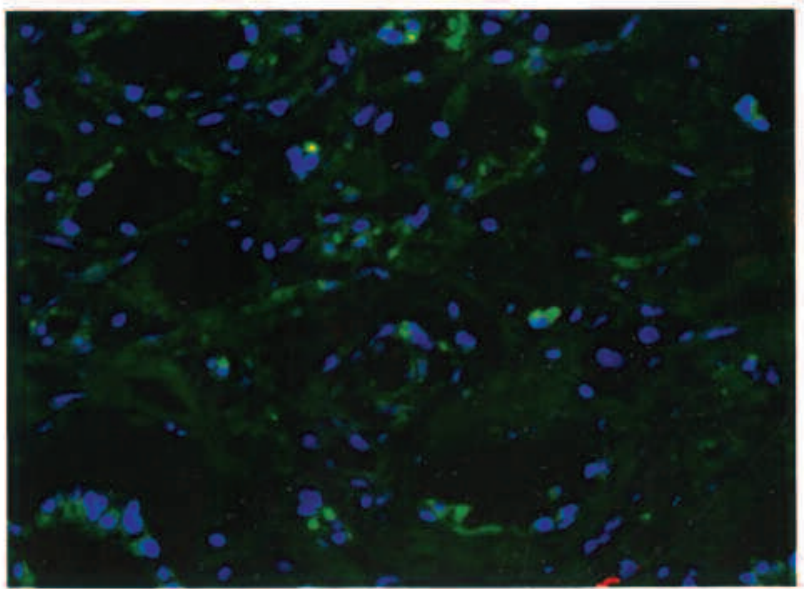

D

Figure 3. XCL1 expression in renal biopsies from patients with WG. Frozen sections of kidney biopsies were stained for XCL1 with a polyclonal rabbit anti-human XCL1 antibody detected by a Cy5-conjugated goat anti-rabbit antibody (red fluorescence). Double-staining for cell-surface antigens was performed by indirect immunofluorescence using monoclonal mouse anti-human CD4-, CD8-, CD68- antibodies and Cy3-conjugated goat anti-mouse antibody as secondary antibody (green fluorescence). XCL1 expression was detected in lymphocytic infiltrates within the interstitium, but not within glomeruli. Double-staining for cell-surface antigens revealed that XCL1 expression was restricted to CD4+ (A) and CD8+ (B) T cells. Colocalization of XCL1 and cell-surface antigens CD4 or CD8, respectively, was demonstrated by yellow staining (arrows). To visualize overlapping signals of both antibodies, intensities of the single antibody staining were evaluated using Cell- $\mathrm{F}^{\circledR}$ software at the level of the horizontal line and displayed as the inserted intensity curves for Cy3 and Cy5. XCL1 was not detected in CD68+ macrophages (C). In addition, no staining was observed in isotype control and renal biopsies of patients with benign nephrosclerosis, IgA nephritis (data not shown), or lupus nephritis, WHO class IV (D).

dose-dependent (Figure 4C) by ELISA and quantitative RT-PCR (data not shown). Results shown in Figure 5 were consistent in at least 3 independent experiments.

XCL1 serum concentrations in WG patients and controls. Sera were obtained from 16 WG patients and 16 age and sex-matched healthy controls. XCL1 levels in WG patients ranged between $0.68 \mathrm{ng} / \mathrm{ml}$ and $48.9 \mathrm{ng} / \mathrm{ml}$ (mean value 7.4 $\mathrm{ng} / \mathrm{ml} \pm 13.9$ ). As shown in Figure 5 A no significant differences were detected between the groups $(\mathrm{p}=0.88)$. According to BVAS scores and CRP levels patients were then classified into those with active $(n=6)$ and with inactive disease $(n=10)$ characterized by complete remission. As shown in Figure 5B, there was no significant difference between these 2 patient groups $(\mathrm{p}=0.71)$.

\section{DISCUSSION}

We analyzed for the first time the expression and functional role of the C-class chemokine lymphotactin (XCL1) in sera, PBMC, and renal biopsies of patients with WG.

Analysis of serum concentrations of XCL1 revealed no significant difference between patients with WG and healthy controls. Further, no correlation was detected between XCL1 serum concentrations and clinical disease activity determined by the BVAS. Because we detected enhanced expression of XCL1 in renal biopsy specimens, serum data may reflect that local activity at sites of active inflammation represents the predominant mode of action of XCL1 in WG. However, our results must be interpreted with caution since treatment effects of immunosuppressive agents (azathio-

$$
\text { Personal non-commercial use only. The Journal of Rheumatology Copyright (C) 2009. All rights reserved. }
$$




\section{A}
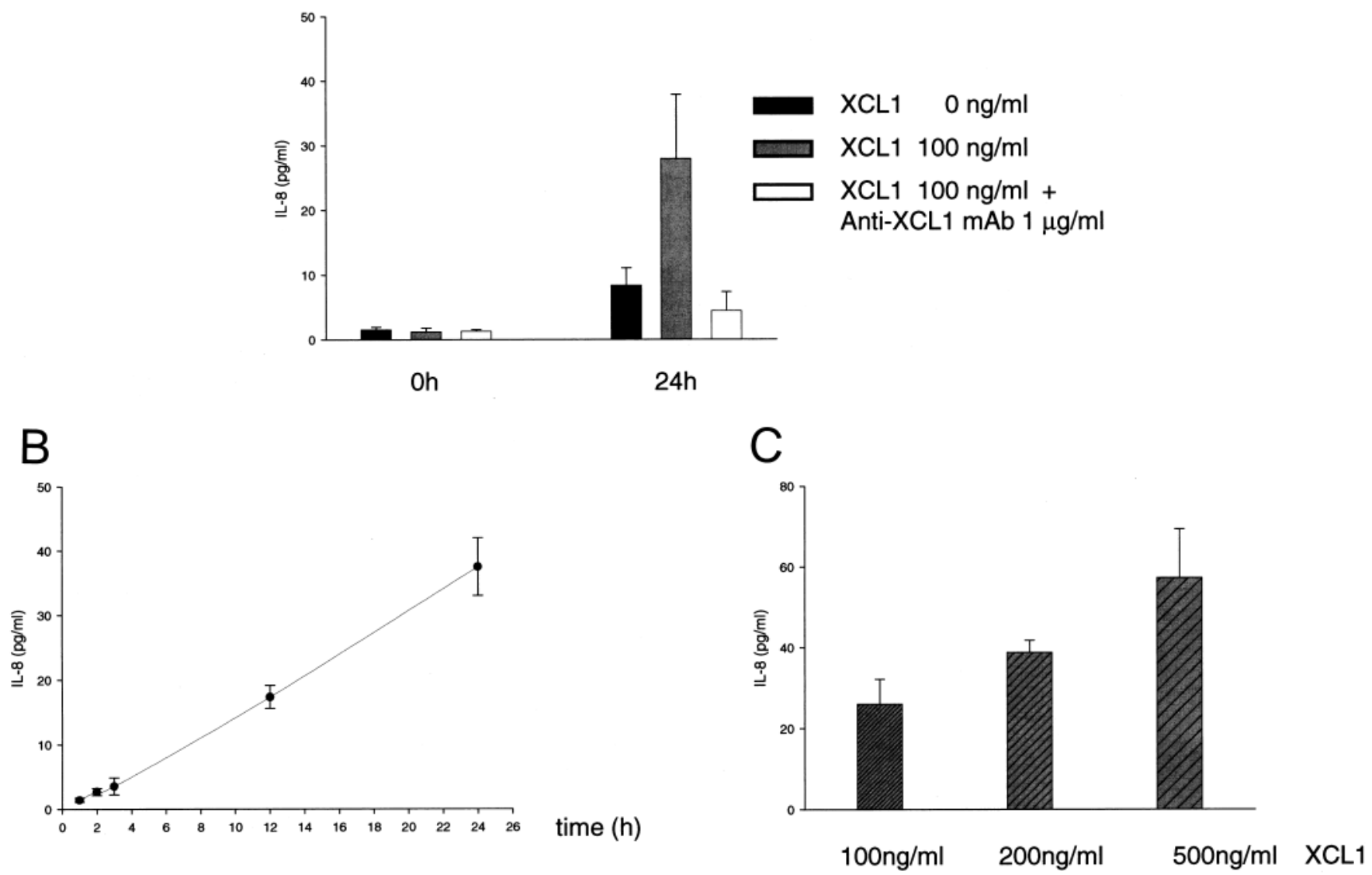

Figure 4. Upregulation of IL-8 production in XCL1-stimulated PMN. (A) PMN isolated from peripheral blood of WG patients were cultured in presence of $100 \mathrm{ng} / \mathrm{ml} \mathrm{XCL1}$ for $24 \mathrm{~h}$. Cell-free supernatants were harvested after $24 \mathrm{~h}$ incubation and assayed for IL-8 release by ELISA. (B) To determine the kinetics of XCL1-induced IL-8 release, PMN were stimulated with $100 \mathrm{ng} / \mathrm{ml} \mathrm{XCL1,} \mathrm{and} \mathrm{culture} \mathrm{supernatants} \mathrm{were} \mathrm{harvested} \mathrm{at} \mathrm{multiple} \mathrm{timepoints} \mathrm{during} \mathrm{incuba-}$ tion. (C) Dose-dependency of XCL1-induced IL-8 release in PMN: PMN were incubated with varying doses of XCL1 (100, 200, 500 ng/ml) over a period of $24 \mathrm{~h}$. Cell-free supernatants were assayed for IL-8 release. Results represent 4 patients; data are mean \pm SE.

prine, methotrexate, and cyclophosphamide; Table 1) could not be excluded. To draw definitive conclusions, serum levels of XCL1 in patients thus have to be analyzed prior to initiation of immunosuppressive therapy.

Flow cytometric analysis of PBMC in WG patients revealed that the immunophenotype of $\mathrm{CD} 4+$ and $\mathrm{CD} 8+\mathrm{T}$ cells was characterized by coexpression of the activation markers CD25, CD69, and HLA-DR. These findings were in accord with previous studies demonstrating a prominent role of HLA-DR+CD4+ T cells during granuloma formation in $\mathrm{WG}^{7}$. Further analysis of the cytokine expression profile of these CD4+ T cells indicated an expansion of Th1-type CD4 $+\mathrm{T}$ cells by enhanced levels of the Th1-related cytokines interferon- $\gamma$ (IFN- $\gamma$ ) and TNF- $\alpha$ in peripheral blood $^{7}$ and at sites of granulomatous inflammation ${ }^{29}$. XCL1 was previously shown to function as a Th1-type cytokine ${ }^{30}$; thus our flow cytometric findings of XCL1 expression in a significantly greater proportion in both CD4+ and CD8+ T cells of WG patients in comparison to controls support the hypothesis of Th1-driven T cell responses in WG.
In accord with our previous flow cytometric data in $\mathrm{RA}^{23}$, another Th1-mediated chronic inflammatory disease, we found XCL1 was mainly expressed in CD4+ and CD8+ $\mathrm{T}$ cells lacking the costimulatory molecule CD28. CD4+CD28- T cells have been detected in peripheral blood and granulomatous lesions of patients with active $\mathrm{WG}^{31}$. Functional analysis has revealed that this $\mathrm{T}$ cell subset is characterized by Th1-type cytokine production (IFN- $\gamma$, TNF- $\alpha$ ) and may play a direct pathogenic role in WG-associated necrotizing vasculitis.

Kidney involvement in WG is histopathologically characterized by disseminated necrotizing vasculitis and interstitial accumulation of monocytes/macrophages and $\mathrm{T}$ cells. Interstitial mononuclear infiltration was shown to be strongly associated with promotion of interstitial fibrosis and renal insufficiency ${ }^{32}$. Further, glomerular mononuclear cell infiltration was found to be associated with crescent formation known to be involved in rapid progression of glomerulonephritis in WG. From renal biopsies of patients with WG we found increased XCL1 expression at Personal non-commercial use only. The Journal of Rheumatology Copyright (C) 2009. All rights reserved. 

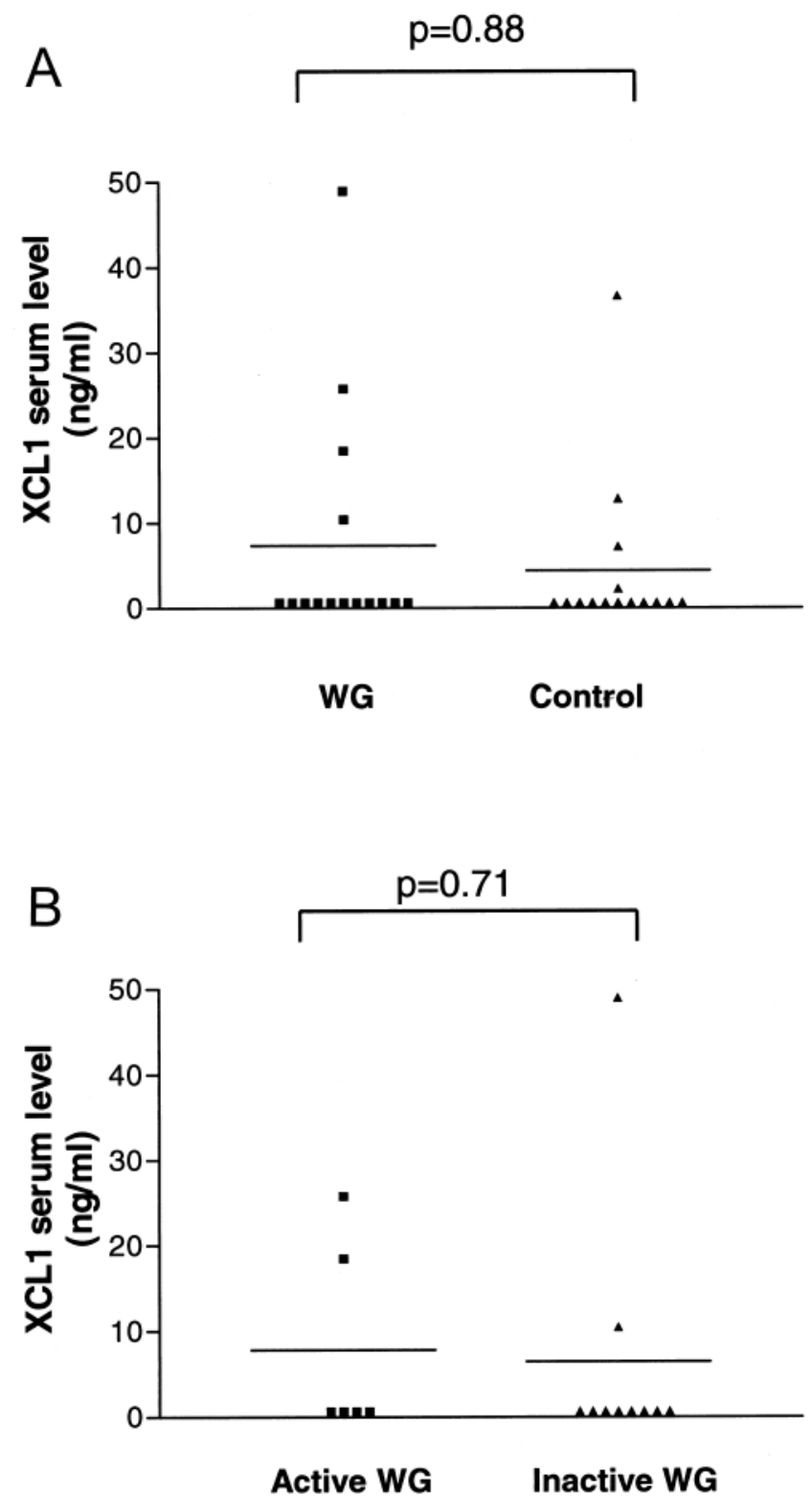

Figure 5. Serum concentrations of XCL1 were measured by ELISA in sera from WG patients $(n=16)$ in comparison to healthy controls $(n=16)$. No significant difference was detected in serum levels of XCL1 between WG patients and controls $(\mathrm{p}=0.88)(\mathrm{A})$. No significant difference was found comparing WG patients with active and inactive disease $(\mathrm{p}=0.71)(\mathrm{B})$.

sites of active inflammation within interstitial CD4+ and CD8+ T cells.

Chemokines known to regulate recruitment and activation of mononuclear cells in inflammatory processes have been analyzed in renal inflammatory diseases ${ }^{33}$. In these studies higher concentrations of both CC- and CXC-chemokines has been observed. In particular, increased expression of both CC-chemokines [regulated on activation normal $\mathrm{T}$ cell expressed and secreted (RANTES, CCL5; MCP-1) $]^{34}$ and CXC-chemokines (IL-8) ${ }^{35}$ have been detected in WG. Further, higher concentrations of fractalkine (CX3CL1) mRNA in renal biopsies and levels of CX3CL1/CX3CR1 in peripheral blood have been reported in patients with cANCA-positive vasculitis ${ }^{36}$. Fractalkine, the sole member of the CX3C subfamily of chemokines, was thus hypothesized to be involved in the pathogenesis of disseminated vasculitis in WG.

XCL1 expression in the kidney has been studied in an animal model of crescentic glomerulonephritis ${ }^{25}$. In accord with data, higher concentrations of XCL1 mRNA was detected in this model in renal tissue of crescentic glomerulonephritis in comparison to controls. XCL1 mRNA was not found in normal glomeruli in these studies. However, in vitro data ${ }^{25}$ showed XCL1 mRNA expression in cultured glomerular mesangial and vascular endothelial cells after stimulation with IL-1ß. In our study XCL1 expression in human WG kidney samples was detected only in interstitial CD4+ and CD8+ T cells. These divergent findings may be due to different pathogenic mechanisms in human WG and crescentic glomerulonephritis in Wistar Kyoto rats induced by injection of antiglomerular basement membrane antibodies. Further, in vitro results of cultured glomerular cells may not reflect the pathogenic mechanisms present in vivo.

Functional analysis of XCL1 in this animal model demonstrated that upregulation of XCL1 mRNA in renal tissue precedes the infiltration of CD8+ T cells in glomeruli known to play an important role in initiation and progression of crescentic glomerulonephritis ${ }^{37}$. Considering its function as a strong chemottractant for $\mathrm{CD} 8+\mathrm{T}$ cells and NK cells ${ }^{9,11,17}$, XCL1 thus may play an important role in lymphocyte trafficking and CD8 T cell accumulation in this animal model of crescentic glomerulonephritis. Further, this mode of action may also be hypothesized for necrotizing vasculitis in WG.

To date, XCL1 expression in human glomerulonephritis has only been studied in IgA nephropathy ${ }^{38}$, the most common form of primary glomerular disease worldwide and one of the major causes of endstage renal disease. Increased mRNA expression of XCL1 was detected within the renal cortex of IgA nephropathy kidney biopsy samples. XCL1 mRNA levels were shown to correlate with the presence of glomerular crescents and tubulointerstitial changes. In accord with our data XCL1 mRNA levels were negligible in both the interstitium and glomeruli in control cases. However, in contrast to our findings in WG, XCL1 was detected by immunohistochemistry in interstitial tryptasepositive cells of IgA nephropathy cases presumed to represent mast cells.

To further characterize the functional role of XCL1 in WG we performed in vitro XCL1 stimulation experiments with PMN isolated from patients with WG. PMN were previously shown to play an important role in the initiation of vascular inflammation in the pathogenesis of WG and were known to express the XCL1 receptor XCR $1^{16}$. In our study 
we show that PMN stimulated with XCL1 release significant amounts of IL- 8 in a dose- and time-dependent manner. The mechanism could be completely revised by addition of a human anti-XCL1 antibody. IL-8 represents a member of the CXC-chemokine class and is mainly produced by monocytes, PMN, and endothelial cells. Functionally, IL-8 has been shown to represent a powerful chemoattractant for PMN in many inflammatory diseases. In WG, increased plasma levels of IL-8 have been described by Torheim, et $a l^{39}$. Further, cANCA ${ }^{6}$ and the autoantigen PR- $3^{40}$ were shown to induce IL-8 release in endothelial cells and monocytes. These studies suggest that IL-8 may play a crucial role in the pathogenesis of disseminated necrotizing granulomatous vasculitis as seen in WG. Our data now support the hypothesis that in WG IL-8 is also produced by PMN. Local production of XCL1 in renal tissue may contribute to vascular inflammation in WG by stimulation of IL-8 release in PMN.

Our study demonstrates enhanced XCL1 expression in $\mathrm{CD} 4+$ and CD8+ $\mathrm{T}$ cells in Wegener's granulomatosis. Considering its function as a T cell attractant, XCL1 may promote $\mathrm{T}$ cell infiltration and trafficking in the pathogenesis of WG. Local expression in interstitial T cells in the kidney may contribute to granulomatous vasculitis by stimulation of the release of IL-8 in PMN, leading to vascular inflammation and tissue damage. Further studies are needed to evaluate if XCL1 may represent a novel therapeutic target molecule in this type of disseminated necrotizing vasculitis.

\section{ACKNOWLEDGMENT}

We gratefully acknowledge the histopathological evaluation of kidney biopsy specimens performed by Prof. H.J. Groene, Department of Cellular and Molecular Pathology, German Cancer Center, Heidelberg, Germany.

\section{REFERENCES}

1. Fauci AS, Wolff SM. Wegener's granulomatosis: studies in eighteen patients and a review of the literature. Medicine 1973;52:535-61.

2. Jennette JC, Falk RJ, Andrassy K, Bacon PA, Churg J, Gross WL, et al. Nomenclature of systemic vasculitides. Proposal of an international consensus conference. Arthritis Rheum 1994;37:187-92.

3. Langford CA. Wegener's granulomatosis: current and upcoming therapies. Arthritis Res Ther 2003;5:180-91.

4. Charles LA, Caldas ML, Falk RJ, Terrell RS, Jennette JC. Antibodies against granule proteins activate neutrophils in vitro. J Leukoc Biol 1991;50:539-46.

5. Porges AJ, Redecha PB, Kimberly WT, Csernok E, Gross WL, Kimberly RP. Anti-neutrophil cytoplasmic antibodies engage and activate human neutrophils via Fc-gamma RIIa. J Immunol 1994;153:1271-80.

6. Ralston DR, Marsh CB, Lowe MP, Wewers D. Antineutrophil cytoplasmic antibodies induce monocyte IL- 8 release. Role of surface proteinase-3, alpha-1-antitrypsin, and Fc-gamma receptors. J Clin Invest 1997;100:1416-24.

7. Ludvíksson BR, Sneller MC, Chua KS, Talar-Williams C, Langford CA, Ehrhardt RO, et al. Active Wegener's granulomatosis is associated with HLA-DR+ CD4+ T cells exhibiting an unbalanced Th1-type T cell cytokine pattern: reversal with IL-10. J Immunol
1998;160:3602-9.

8. Rollins BJ. Chemokines. Blood 1997;90:909-28.

9. Kelner GS, Kennedy J, Bacon KB, Kleyensteuber S, Largaespada DA, Jenkins NA, et al. Lymphotactin: A cytokine that represents a new class of chemokine. Science 1994;266:1395-9.

10. Yoshida T, Imai T, Kakizaki M, Nishimura M, Yoshie O. Molecular cloning of a novel $\mathrm{C}$ or gamma type chemokine, SCM-1. FEBS Lett 1995;360:155-9.

11. Muller S, Dorner B, Korthauer U, Mages HW, D’Apuzzo M, Senger G, et al. Cloning of ATAC, an activation-induced, chemokine-related molecule exclusively expressed in CD8+ T lymphocytes. Eur J Immunol 1995;25:1744-8.

12. Boismenu R, Feng L, Xia YY, Chang JC, Havran WL. Chemokine expression by intraepithelial $\partial \mathrm{T}$ cells: implications for the recruitment of inflammatory cells to damaged epithelia. J Immunol 1996;157:985-92.

13. Rumsaeng V, Vliagoftis H, Oh CK, Metcalfe DD. Lymphotactin gene expression in mast cells following Fc ( ) receptor I aggregation: Modulation by TGF- $\beta$, IL-4, dexamethasone, and cyclosporin A. J Immunol 1997;158:1353-60.

14. Hedrick JA, Saylor V, Figueroa D, Mizoue L, Xu Y, Menon S, et al. Lymphotactin is produced by NK cells and attracts both NK cells and T cells in vivo. J Immunol 1997;158:1533-40.

15. Yoshida T, Imai T, Kakizaki M, Nishimura M, Takagi S, Yoshie O. Identification of single $\mathrm{C}$ motif-1/lymphotactin receptor XCR1. J Biol Chem 1998;273:16551-4.

16. Huang H, Li F, Cairns CM, Gordon JR, Xiang J. Neutrophils and B cells express XCR1 receptor and chemotactically respond to lymphotactin. Biochem Biophys Res Commun 2001;281:378-82.

17. Kennedy J, Kelner GS, Kleyensteuber S, Schall TJ, Weiss MC, Yssel H, et al. Molecular cloning and functional characterization of human lymphotactin. J Immunol 1995;155:203-9.

18. Dorner B, Muller S, Entschladen F, Schroder JM, Franke P, Kraft R, et al. Purification, structural analysis, and function of natural ATAC, a cytokine secreted by CD8+ T cells. J Biol Chem 1997;272:8817-23.

19. Giancarlo B, Silvano S, Albert Z, Mantovani A, Allavena P. Migratory response of human natural killer cells to lymphotactin. Eur J Immunol 1996;26:3238-41.

20. Middel P, Thelen P, Blaschke S, Polzien F, Reich K, Blaschke V, et al. Expression of the T-cell chemoattractant chemokine lymphotactin in Crohn's disease. Am J Pathol 2001;159:1751-61.

21. Bradley LM, Asensio VC, Schioetz LK, Harbertson J, Krahl T, Patstone G, et al. Islet-specific Th1, but not Th2, cells secrete multiple chemokines and promote rapid induction of autoimmune diabetes. J Immunol 1999;162:2511-20.

22. Tran EH, Kuziel WA, Owens T. Induction of experimental autoimmune encephalomyelitis in C57BL/6 mice deficient in either the chemokine macrophage inflammatory protein-1 alpha or its CCR5 receptor. Eur J Immunol 2000;30:1410-5.

23. Blaschke S, Middel P, Dorner BG, Blaschke V, Hummel KM, Kroczek RA, et al. Expression of activation-induced, $\mathrm{T}$ cell derived and chemokine-related cytokine/lymphotactin and its functional role in rheumatoid arthritis. Arthritis Rheum 2003;48:1858-72.

24. Wang JD, Nonomura N, Takahara S, Li BS, Azuma H, Ichimaru N, et al. Lymphotactin: a key regulator of lymphocyte trafficking during acute graft rejection. Immunology 1998;95:56-61.

25. Natori Y, Ou ZL, Yamamoto-Shuda Y, Natori Y. Expression of lymphotactin mRNA in experimental crescentic glomerulonephritis. Clin Exp Immunol 1998;113:265-8.

26. Leavitt RY, Fauci AS, Bloch DA, Michel BA, Hunder GG, Arend WP, et al. The American College of Rheumatology 1990 criteria for the classification of Wegener's granulomatosis. Arthritis Rheum 1990;33:1101-7.

27. Luqmani RA, Bacon PA, Moots RJ, Janssen BA, Pall A, Emery P,

$$
\text { Personal non-commercial use only. The Journal of Rheumatology Copyright (c) 2009. All rights reserved. }
$$


et al. Birmingham Vasculitis Activity Score (BVAS) in systemic necrotizing vasculitis. QJM 1994;87:671-8.

28. Dubravec DB, Spriggs DR, Mannick JA, Rodrick ML. Circulating human peripheral blood granulocytes synthesize and secrete tumor necrosis factor. Proc Natl Acad Sci USA 1990;87:6758-61.

29. Csernok E, Trabandt A, Mueller A, Wang GC, Moosig F, Paulsen J, et al. Cytokine profiles in Wegener's granulomatosis: predominance of type 1 (Th1) in the granulomatous inflammation. Arthritis Rheum 1999;42:742-50.

30. Dorner BG, Scheffold A, Rolph MS, Hüser MB, Kaufmann SH, Radbruch A, et al. MIP-1, MIP-1ß, RANTES, and ATAC/ lymphotactin function together with IFN- $\gamma$ as type 1 cytokines. Proc Natl Acad Sci USA 2002;99:6181-6.

31. Komocsi A, Lamprecht P, Csernok E, Mueller A, Holl-Ulrich K, Seitzer U, et al. Peripheral blood and granuloma CD4+CD28- T cells are a major source of interferon-gamma and tumor necrosis factor-alpha in Wegener's granulomatosis. Am J Pathol 2002;160:1717-24.

32. Atkins RC, Nikolic-Paterson DJ, Song Q, Lan HY. Modulators of crescentic glomerulonephritis. J Am Soc Nephrol 1996;7:2271-8.

33. Schlondorff D, Nelson PJ, Luckow B, Banas B. Chemokines and renal disease. Kidney Int 1997;51:610-21.

34. Cockwell P, Howie AJ, Adu D, Savage CO. In situ analysis of CC-chemokine mRNA in human glomerulonephritis. Kidney Int 1998;54:827-36.
35. Cockwell P, Brooks CJ, Adu D, Savage CO. Interleukin-8: a pathogenetic role in antineutrophil cytoplasmic autoantibody-associated glomerulonephritis. Kidney Int 1999;55:852-63.

36. Bjerkeli V, Damås JK, Fevang B, Holter JC, Aukrust P, Frøland SS. Increased expression of fractalkine (CX3CL1) and its receptor, CX3CR1, in Wegener's granulomatosis - possible role in vascular inflammation. Rheumatology 2007;46:1422-7.

37. Kawasaki K, Yaoita E, Yamamoto T, Kihara I. Depletion of CD8 positive cells in nephrotoxic serum nephritis of WKY rats. Kidney Int 1992;41:1517-26

38. Ou ZL, Hotta O, Natori Y, Sugai H, Taguma Y, Natori Y. Enhanced expression of $\mathrm{C}$ chemokine lymphotactin in IgA nephropathy. Nephron 2002;91:262-9.

39. Torheim EA, Yndestad A, Bjerkeli V, Halvorsen B, Aukrust P, Frøland SS. Increased expression of chemokines in patients with Wegener's granulomatosis - modulating effects of methylprednisolone in vitro. Clin Exp Immunol 2005;140:376-83.

40. Berger SP, Seelen MA, Hiemstra PS, Gerritsma JS, Heemskerk E, van der Woude FJ. Proteinase-3, the major autoantigen of Wegener's granulomatosis, enhances IL-8 production by endothelial cells in vitro. J Am Soc Nephrol 1996;7:694-701. 